\title{
Environmental Stress Cracking Resistance of Halloysite Nanoclay-Polyester Nanocomposites
}

\author{
Mohd Shahneel Saharudin*, Jiacheng Wei, Islam Shyha, Fawad Inam \\ Department of Mechanical and Construction Engineering, Faculty of Engineering and Environment, Northumbria University, \\ Newcastle, UK \\ Email: *mohd.saharudin@northumbria.ac.uk
}

How to cite this paper: Saharudin, M.S. Wei, J.C., Shyha, I. and Inam, F. (2017) Environmental Stress Cracking Resistance of Halloysite Nanoclay-Polyester Nanocomposites. World Journal of Engineering and Technology, 5, 389-403.

https://doi.org/10.4236/wjet.2017.53033

Received: May 15, 2017

Accepted: July 9, 2017

Published: July 12, 2017

Copyright () 2017 by authors and Scientific Research Publishing Inc. This work is licensed under the Creative Commons Attribution International License (CC BY 4.0).

http://creativecommons.org/licenses/by/4.0/

\section{Open Access}

\begin{abstract}
The environmental stress cracking resistance of halloysite nanoclay-polyester nanocomposites was investigated using fracture mechanics approach. The incorporation of halloysite nanoclay was found to improve the environmental stress cracking resistance of the nano-composites. The storage modulus of nano-composites measured by dynamic mechanical analysis increased remarkably as a function of halloysite nanoclay content. At $0.7 \mathrm{wt} \%$ nanoclay, the $T_{\mathrm{g}}$ improved from $72^{\circ} \mathrm{C}$ to $76^{\circ} \mathrm{C}$. The fracture toughness increased up to $33 \%$ and time to failure improved $155 \%$ with the addition of $0.7 \mathrm{wt} \%$ of halloysite nanoclay. The maximum microhardness was found $119 \%$ higher for the same nano-filler concentration compared to monolithic polyester. The reinforcement with $1 \mathrm{wt} \%$ showed lower fracture toughness due to agglomerations of nanoclay which act as flaws. The presence of agglomerates weakened the bond between nano-particles and matrix hence reduces the environmental stress cracking resistance by halloysite nanoclay reinforcement.
\end{abstract}

\section{Keywords}

Halloysite Nanoclay, Environmental Stress Cracking Resistance, Nanocomposites, Polyester

\section{Introduction}

Nano-composite materials were typically used in various components and constructions of wind turbine blades, aircraft, automobile, sporting goods and marine structures [1] [2] [3]. However, the disadvantage of using polymer based materials is the deterioration mechanical properties triggered by aggressive liquid contact such as methanol, isopropanol and acetone [4] [5]. Environmental stress cracking failure can occur on polyester based products far below the fracture strength since most composites subjected to external stress are vulnerable to 
aggressive liquid exposure [6] [7]. Bottles, vessels, and pipes are normally in contact with liquid media which leads to deterioration in mechanical properties [8] [9]. In certain applications of polymer nano-composites, the interaction with liquid environment is inevitable and could lead to failure. The liquid exposure causes the environmental stress cracking failure and degradation to the polymer matrix. The degree of liquid absorption and polymer degradation can be reduced by using nano-fillers such as nanoclay. Alamri and Low in their research reported that halloysite nanoclays were able to reduce water absorption and increase the mechanical properties of epoxy through uniform dispersion [10] [11].

Halloysite nanoclay is in form of tubular structure produced from natural deposits in countries such as China, America, Brazil and France [12] [13]. The use of nano-particles with polymers could enhance fracture toughness without compromising properties such as strength, modulus, thermal stability, flame retardancy and glass transition temperature [14] [15]. In nature, halloysite nanoclay is nontoxic and has tuneable release rates which make them suitable in biomedical applications [16]. Another advantage of clay/polymer nanocomposites mentioned by other researcher is that, the optical clarity of the polymer is not significantly reduced [17]. The tubular structure, low percolation and good aspect ratio make nanoclay a potential reinforcement for unsaturated polyester resin. The unique properties make them as excellent candidate for drug delivery, water purification and polymer composites applications [18]. Halloysite nanoclay, either as it is or after modification, is recognized as one of the materials of the $21^{\text {st }}$ century because it is abundant, relatively cheap and environmentally safe [19]. For thermoplastic based polymers, the cracking agent does not cause a chemical degradation of the polymer, instead penetrates slowly into the polymer matrices under tension and causes hydrostatic pressure which speed up the cracking propagation and produces catastrophic failure of plastic components [20] [21] [22]. Hojo et al. in their publication revealed that the degradation of polyester resin belonged to penetration type [23]. Our previous studies showed that the incorporation of halloysite nanoclay significantly improved flexural strength, tensile strength, microhardness and glass transition temperature of polyester [15] [17] [24] [25] [26].

This study is aimed to improve knowledge of the environmental stress cracking resistance of halloysite nanoclay-polyester nanocomposites exposed to aggressive environment. Various research publications have discussed the engineering properties of polymer nano-composites exposed to water [10] [27]. However, there is no publication where halloysite nanoclay-polyester nanocomposites subjected to methanol and simultaneous constant loading. The fracture mechanics approach were previously used by Moskala [28] and Friedrich [7], both of them have never used the fracture mechanics approach to obtain fracture toughness $\left(K_{1 \mathrm{C}}\right)$ without the presence of liquid medium. This is simply because the environmental stress cracking failure only occurred when there is interaction of chemical reaction and stress field at crack tip. In the past, the application of fracture mechanics approach to study Environmental Stress Crack- 
ing resistance has been carried out only on thermoplastics polymers. This can be attributed to their brittle property due to the high crosslinking level [29]. We decided to use polyester (thermoset based polymer) to study the effect of direct methanol exposure on mechanical properties of halloysite nanoclay polyester nanocomposites. The high speed digital camera (EOS 600D), capable to capture 60 frame per second (FPS), which allow images to be captured during the fracture. FPS (frame per second) is a measurement for number of unique consecutive images a camera can handle each second. The final image before fracture gave the highest deformation and was measured using ImageJ software. In this research the polyester resins was used since it is one of the most commonly used thermosetting polymers because of their low cost and versatility [30] [31] [32] [33]. On the other hand, methanol is always a desirable choice as a transportation fuel due to its efficient combustion, ease of availability and distribution [24] [34]. The contact between polyester and methanol is likely to occur in automotive industry. Based on this possible interaction, the selection of polyester and methanol was selected to study the effect of halloysite reinforcement on the environmental stress cracking resistance.

\section{Experimental Sections}

\subsection{Materials}

Halloysite nanoclay with tubular structure was used as filler and bought from Sigma Aldrich, UK. The halloysite nanoclay diameter is between $30-70 \mathrm{~nm}$ with length of $1-4 \mu \mathrm{m}$ (Figure 1). The density of nanoclay is $2.53 \mathrm{~g} / \mathrm{cm}^{3}$ with surface area of $64 \mathrm{~m}^{2} / \mathrm{g}$. The unsaturated polyester resin (NORSODYNE O $12335 \mathrm{AL}$ ) was bought from East Coast Fibreglass, UK. The resin density is $1.2 \mathrm{~g} / \mathrm{cm}^{3}$. Methyl ethyl ketone peroxide solution in dimethyl phthalate was used as catalyst also acquired from East Coast Fibreglass, UK. To produce monolithic polyester samples, the resin (Norsodyne O $12335 \mathrm{Al}$ ) was mixed with catalyst (Butanox M-50) in a polyester: catalyst ratio of 98:2.

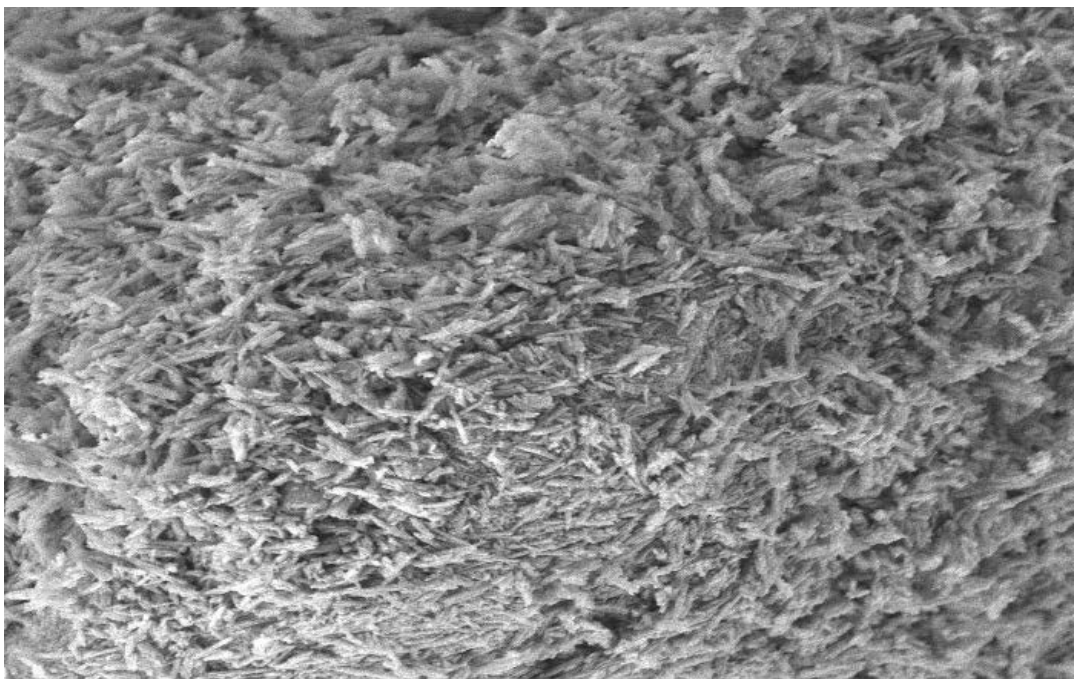

Figure 1. SEM image of halloysite nanoclay. 


\subsection{Samples Production}

By using bath sonicator, the fillers were homogenously dispersed in unsaturated polyester resin for 30 minutes. Following thorough hand mixing for 5 minutes, the mixture of resin and catalyst then transferred into moulds for $24 \mathrm{~h}$ curing process at room temperature followed by post curing at $60^{\circ} \mathrm{C}$ for another $2 \mathrm{~h}$. Four different weight fractions of nanoclay ( $0.1 \mathrm{wt} \%, 0.3 \mathrm{wt} \%, 0.7 \mathrm{wt} \%$ and 1.0 wt\%) were used to reinforce the polyester. Dynamic Mechanical Analyzer (DMA 8000 , Perkin-Elmer) was used to determine dynamic storage modulus (E') and loss modulus (E") of the samples. The loss factor $\tan \delta$ was calculated as the ratio $\left(E^{\prime \prime} / E^{\prime}\right)$. The glass transition temperature $\left(T_{\mathrm{g}}\right)$ was taken as the temperature value at the peak of $\tan \delta$ curves. Rectangular test specimens of dimensions $20 \times 6 \times 3$ $\mathrm{mm}$ were cut from failed compact tension (CT) samples and tested with a single cantilever clamp. Temperature sweep method was applied (temperature ramp from $30^{\circ} \mathrm{C}$ to $130^{\circ} \mathrm{C}$ at $5^{\circ} \mathrm{C} / \mathrm{min}^{-1}$ ) at a constant frequency of $1 \mathrm{~Hz}$. The densification of samples was carried out according to ASTM standard D792. The density of polyester, catalyst and water were, $1.1,1.2$ and $0.9975 \mathrm{~g} / \mathrm{cm}^{3}$ respectively. Equation (1) and Equation (2) were used to obtain the densification percentage.

$$
\begin{gathered}
\text { Experimental density }=\frac{\text { Weight in air }}{\text { Weight in air }- \text { weight in water }} \times \text { Density of water } \\
\text { Densification }(\%)=\frac{\text { Experimental density }}{\text { Theoretical density }} \times 100
\end{gathered}
$$

\subsection{Characterisation}

To study the fracture toughness of nanocomposites, a compact tension (CT) examination according to ASTM D5045-99 was performed at room temperature. CT samples were produced according to the dimension shown in Figure 2. The time to failure was also recorded to investigate the difference of each nanocomposites. A schematic illustration of the experimental work of the fracture mechanics test is shown in Figure 3. The crack length was monitored and all images were saved using Canon EOS 600D and fracture toughness analysis. All tests were performed at room temperature $22^{\circ} \mathrm{C} \pm 1^{\circ} \mathrm{C}$ and constant load of $12 \mathrm{~N}$ was applied. The pre-crack was surrounded by the stress cracking agent during

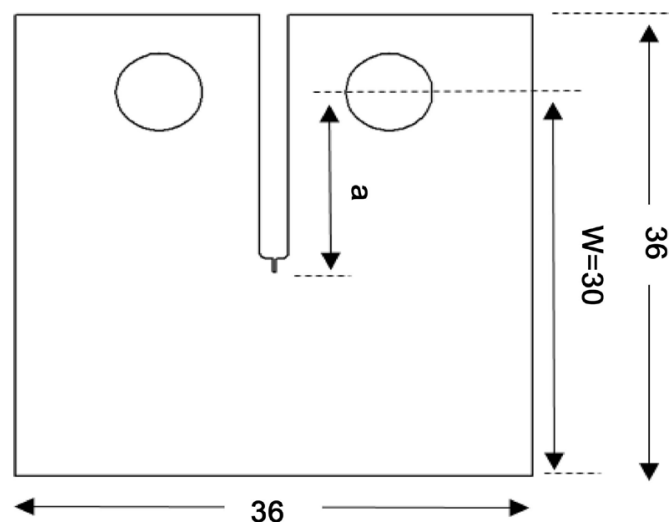

Figure 2. Dimensions of sample used for fracture toughness test in $\mathrm{mm}$. 


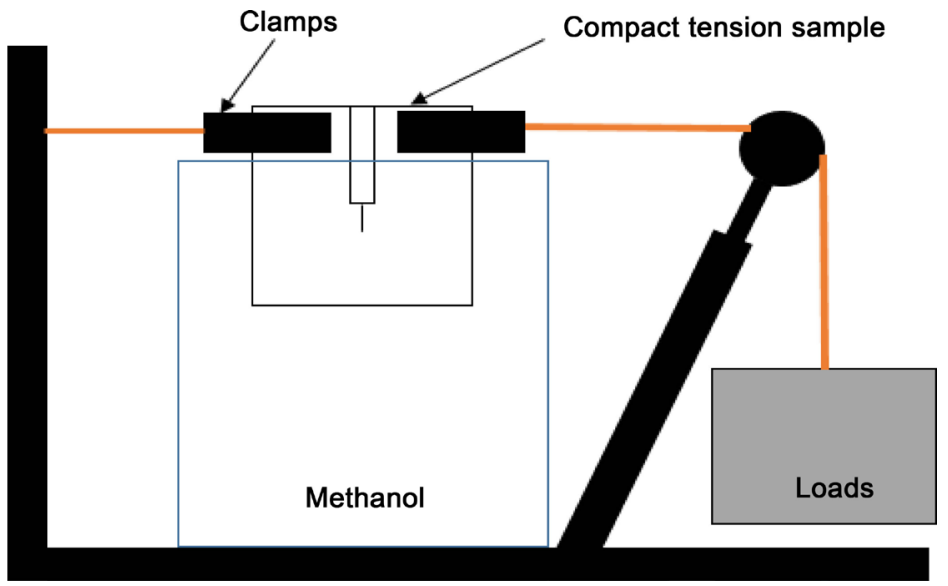

Figure 3. Schematic of test set up (not drawn to scale).

the testing. The stress cracking agent used in all tests was methanol (CAS-No. 67-56-1:).

After the images were captured and saved in the computer, the crack length was measured using ImageJ software for fracture toughness $\left(\mathrm{K}_{1 \mathrm{C}}\right)$ calculation. ImageJ is an image processing program created by NIH Image. The software could obtain length, area and pixel value statistics of user-defined selections. A standard line $(10 \mathrm{~mm})$ was drawn on the sample as a reference before the experiment started. In the ImageJ software this line can be used as a scale and useful for measuring the final deformation of sample. The pre-crack was obtained by slightly tapping a razor blade into the bottom of the saw slot in the samples. The pre-crack length $a_{o}$, was made in between $0.45<a_{o} / \mathrm{W}<0.55$. The specific fracture toughness $K_{1 C}$ was obtained from the equation 3 , where B $(3 \mathrm{~mm})$ and $\mathrm{W}(36 \mathrm{~mm})$ characterize the specimen dimensions. The fractured surfaces of failed specimen were examined by using SEM FEI Quanta 200. The fractured samples which exposed to the aggressive environment (methanol) were cut and a layer of gold was applied using Emscope sputter coater model SC500A. The Vickers microhardness test was performed by using Buehler Micromet II (Spectrographic, Bradford, UK) to evaluate the hardness values of all specimens. For this experiment, the load selected was $200 \mathrm{~g}$ for the duration of $10 \mathrm{~s}$. The surface roughness measurement was performed using Alicona Infinite Focus optical microscope. The focus-follow technique encompasses the usage of a moving lens that retains a spot of light focused at the sample surface [35]. An electric motor controls the upright movement and interacts to the sample surface [36] [37].

$$
K_{1 C}=f\left(\frac{a_{o}}{W}\right) \cdot\left(\frac{F}{B W^{\frac{1}{2}}}\right)
$$

The macro crack length is $a, F$ is load and $\mathrm{f}(\mathrm{a} / \mathrm{W})$ is the calibration factor for CT samples, which is as follows:

$$
f\left(\frac{a}{W}\right)=\left[\left(2+\frac{a}{W}\right) /\left(1-\frac{a}{W^{\frac{3}{2}}}\right)\right] \cdot\left[0.866+4.64(a / W)-13.32(a / W)^{2}+14.72(a / W)^{3}-5.6(\mathrm{a} / \mathrm{W})^{4}\right] \text {. }
$$




\section{Results and Discussion}

The increase of pre-crack length before failure is a very important information to obtain the $K_{1 \mathrm{C}}$ values. The crack initiation and its propagation can be seen in Figure 4(a). The final image of $0.7 \mathrm{wt} \%$ nanocomposite is shown in Figure 4(a). The sample broke into two pieces A (fixed end) and B (direction of applied force). The image was found moved on the sided of applied load. Images in grey scales are presented in Figure 4(b). It can be observed that the difference between pre-crack length $(t=0 \mathrm{~s})$ and final length $(t=2103 \mathrm{~s})$ is small but measurable. At $t=2104 \mathrm{~s}$ the sample broke to two pieces as shown below. Another interesting observation, the damage area was found to grow in size as well as the crack opening displacement.

The dynamic mechanical properties of the nano-composites are presented in Figure 5 and Figure 6 . The $\tan \delta$ is presented in Figure 5. The tangent of the loss angle $(\tan \delta$ ) for the nano-composites decreased with increasing volume fraction of halloysite nanoclay. This is consistent with the established trend of increasing storage modulus. The maximum $\tan \delta$ was observed in case of monolithic polyester (1.14) and the minimum $\tan \delta$ was found in case of $0.7 \mathrm{wt} \%$ of halloysite nanoclay reinforcement $(0.96)$. The storage moduli are shown in Figure 6. The storage moduli increased with increasing clay loading as is usually obtained in other polymer-clay system. [38] [39] [40] [41] A shift in storage moduli can be observed in all cases of reinforcement which can be attributed to the stiff nature of the clay fillers and also due to the combined effect of the high aspect ratio and fine dispersion of halloysite nanoclay [14] [42]. A shift in storage moduli can be observed in all cases of reinforcement which can be attributed to the stiff nature of the clay fillers and due to the combined effect of the high aspect ratio and fine dispersion of halloysite nanoclay. The minimum storage modulus increment was observed in case of $1 \mathrm{wt} \%$ reinforcement (3.76 GPa to $22.14 \mathrm{GPa}$ ). This is an
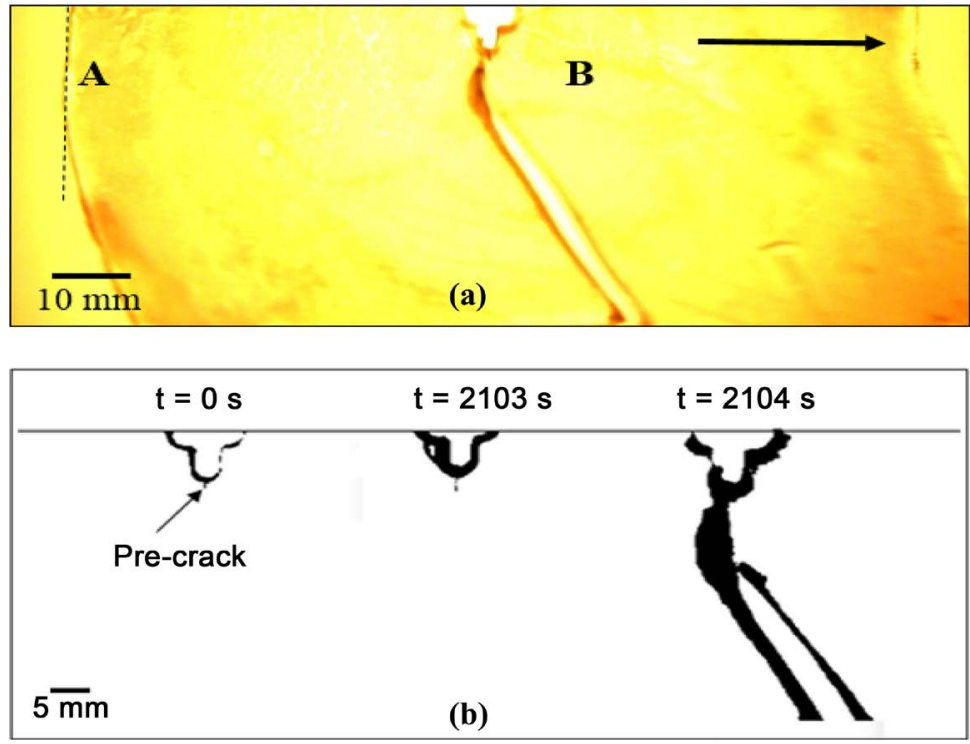

Figure 4. Development of crack propagation as a function of times: (a) original image before fracture (b) images in grey scale after processing with ImageJ software. 


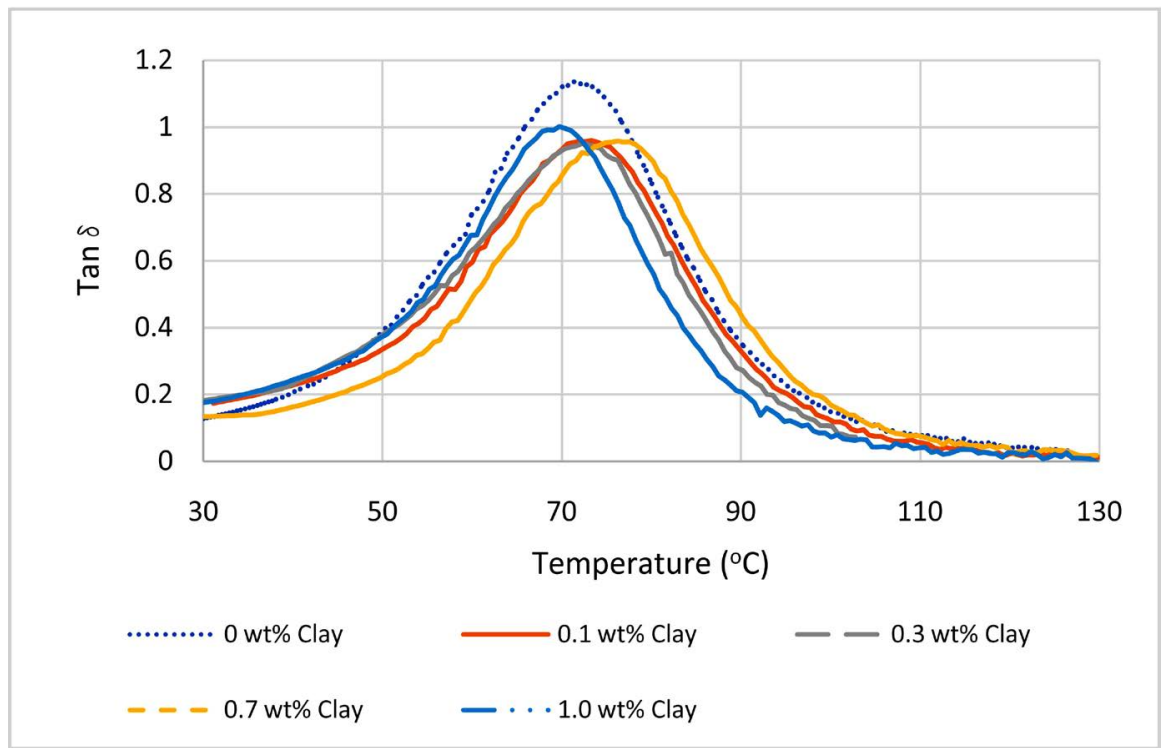

Figure 5. Tan delta of polyester-nanocomposites.

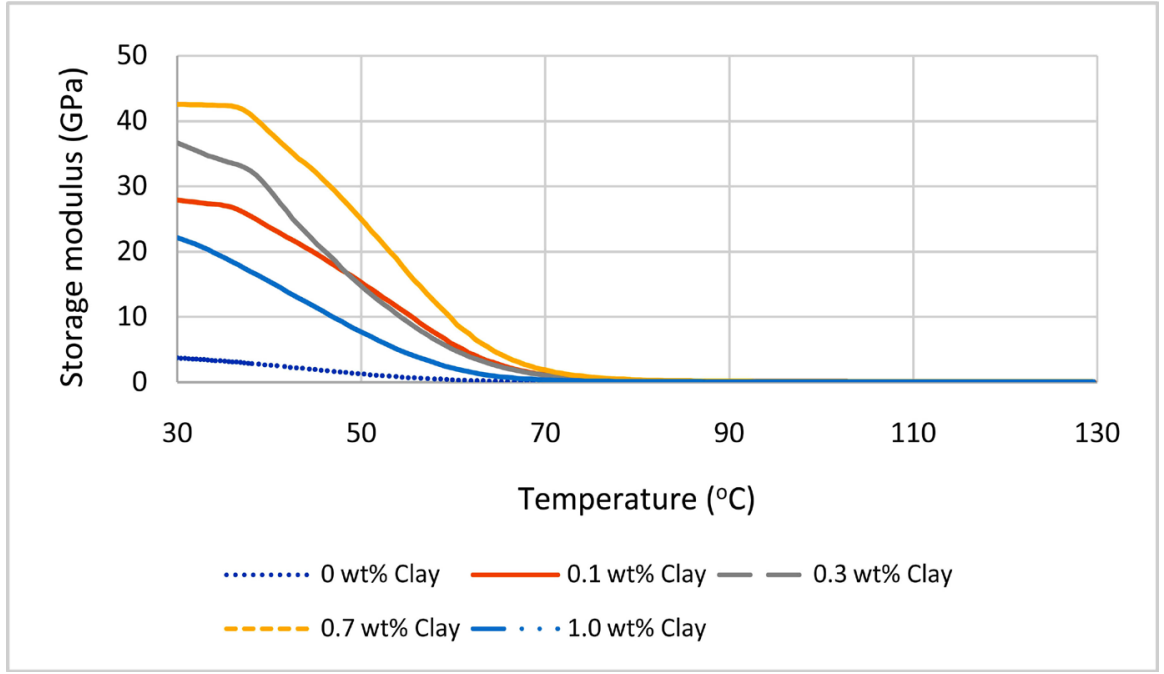

Figure 6. Storage modulus of polyester and its nano-composites.

indication that nanoclay clusters may act as flaws hence lowering the storage modulus from what was expected. However, the storage modulus was much higher than monolithic polyester. The glass transition temperature is presented in Figure 7. It can be seen that the $T_{\mathrm{g}}$ improvement due to the restriction of the segmental motion of the polymers chain located near the halloysite nanoclay surface [43]. The maximum $T_{\mathrm{g}}$ increased from $71.9^{\circ} \mathrm{C}$ to $75.9^{\circ} \mathrm{C}$ in case of 0.7 wt\% reinforcement.

The densification of samples is shown in Figure 8(a). In general the decrease in densification for samples can be linked to the presence of air bubbles within the samples and agglomeration of nano-filler particles [44] [45] [46]. The densification of samples at $1 \mathrm{wt} \%$ reinforcement is about $98.3 \%$, which is the lowest value compared to other composites. It is almost impossible to prevent formation of micro pores in samples fabrication, especially at higher filler content 


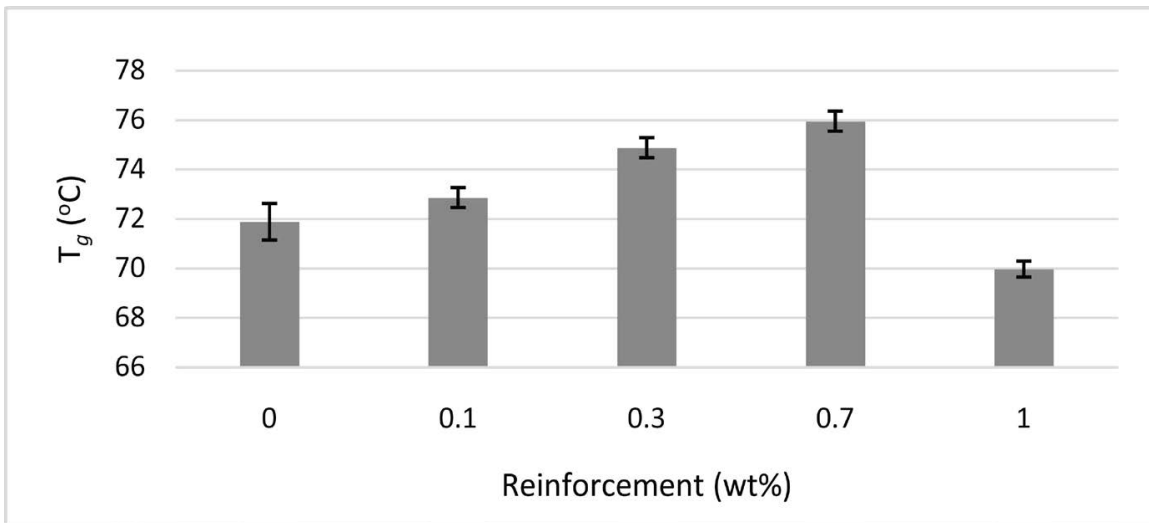

Figure 7. Glass transition temperature of nanocomposites.

when the viscosity increased. [47] As a result, some mechanical properties were not enhanced as anticipated particularly in case of $1 \mathrm{wt} \%$ halloysite nanoclay reinforcement. Apart from that, a drop in densification at $1 \mathrm{wt} \%$ reinforcement indicate that halloysite nanoclay did not fill in pores and may prevented the escape of volatiles [37]. The variation in mode-I fracture toughness $\left(K_{\mathrm{IC}}\right)$ is shown in Figure 8(b). The minimum increase in $K_{1 \mathrm{C}}$ was from $1.51 \mathrm{MPa} \cdot \mathrm{m}^{1 / 2}$ to 1.77 MPa.m ${ }^{1 / 2}(17.2 \%$ increase) in case of $0.1 \mathrm{wt} \%$ halloysite nanoclay. The maximum increase was observed in case of $0.7 \mathrm{wt} \%$ with increment to $2 \mathrm{MPa} \cdot \mathrm{m}^{1 / 2}(32.5 \%$ increase). The incorporation of halloysite nanoclay improved the fracture toughness of the nano-composites. The catastrophic time to failure graph is also shown in Figure 8(d). When samples subjected to constant load and liquid media exposure, monolithic polyester recorded the quickest time to failure compared to other nano-composites with just 867 seconds. It is also noted that the time to failure improved steadily with the increasing halloysite nanoclay. The minimum improvement was recorded at $0.1 \mathrm{wt} \%$ halloysite nanoclay $(60.7 \%$ improvement). At $0.7 \mathrm{wt} \%$ reinforcement, the time to failure increased to 2208 seconds (155\% increase).

The variation in Vickers microhardness is shown in Figure 8(d). The minimum improvement of Vickers microhardness was from $43.3 \mathrm{HV}$ to $56.2 \mathrm{HV}$ (29.8\%). The Vickers microhardness improved gradually with the addition of halloysite nanoclay and reached the maximum value of $94.8 \mathrm{HV}$ in case of 0.7 $\mathrm{wt} \%$ reinforcement (119\% increase). When the tip of indenter placed on the surface of the nano-composites, good resistance was observed and high value of hardness is obtained. This is because halloysite nanoclays tend to fill in any existing micropores, hence restrict the movement of polymer chain, thus the microhardness values was improved. The microhardness value dropped from 94.8 $\mathrm{HV}$ to $65.5 \mathrm{HV}$ (30.9\% decrease) in case of $1 \mathrm{wt} \%$ compared to $0.7 \mathrm{wt} \%$ reinforcement.

During microhardness test, the indenter sits on soft surface and plasticized surface of the monolithic polyester. The indenter did not encounter resistance because it was hitting at the location of vacancies within the sample. Besides that, the softening of polymer matrix occurred because of methanol exposure. 

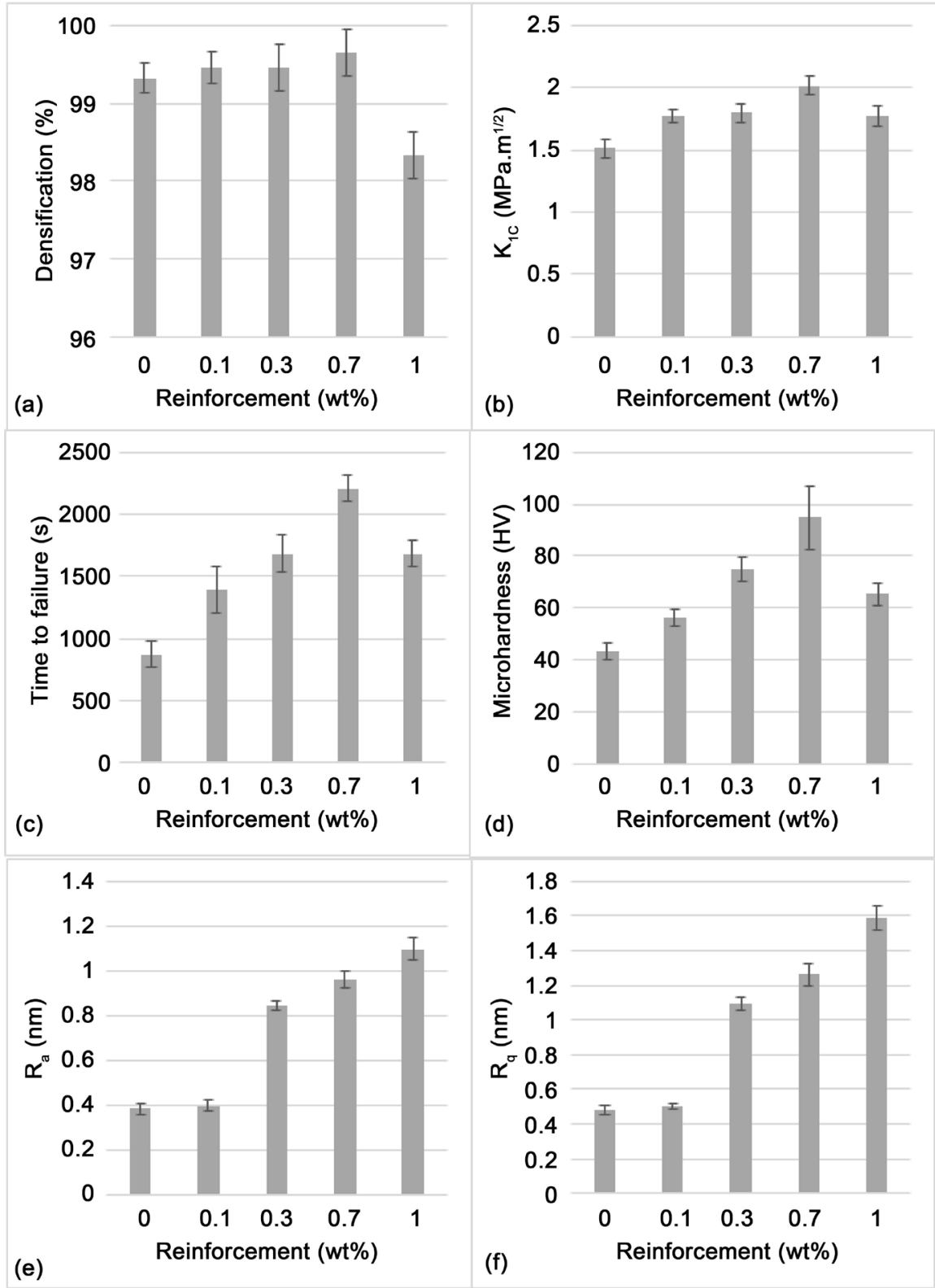

Figure 8. (a) Densification of samples (b) fracture toughness, $K_{1 \mathrm{C}}$ (c) time to failure (d) Vickers microhardness (e) $R_{\mathrm{a}}$ (average surface roughness)(f) $R_{\mathrm{q}}$ (root mean square value).

The softening of polymer matrix predominantly occurred to monolithic polyester samples. In contrast, samples reinforced with halloysite nanoclay showed less softening effect caused by methanol exposure. For higher microhardness values, the indenter hits perfectly on halloysite nanoclay tubes and the nano-filler can provide excellent resistant toward indentation because of its high surface ratio [35]. Previous research also revealed that methanol could have the highest diffusion rate and greatest degree of swelling on monolithic polyester [48]. When mixed together, the liquid barrier properties of unsaturated polyester resin were improved by the reinforcement of the halloysite which was well-suited with the polymer when mixed together. This was achieved by reducing the void and increasing the penetration route of liquid [49]. Inorganic filler particles such 
as halloysite at nano-size can be used as reinforcement in the epoxy to produce nanocomposite. Nanoparticles dispersion into unsaturated polyester resins could be the best way in improving the integrity and sturdiness of coatings because the fillers shall eliminate micro voids and provide crack bridging. Moreover, dispersed nanoparticles can also prevent unsaturated polyester from forming aggregates especially during curing process. As a result, more homogenous coating can be produced. This is because nano-fillers can reduce micro-pores formation because of shrinkage during curing and act as a connection that joining more molecules together. Therefore, total free volume can be reduced and crosslink density increased. Unsaturated polyester resins comprising nanoparticles addition provide excellent corrosion protection and reduce the formation of cluster or blister. The variation in surface of roughness $\left(R_{a}\right)$ measurement is shown in Figure $8(e)$. This measurement frequently used roughness amplitude parameter as it measures the roughness of samples surfaces [36]. The minimum increase of $\mathrm{R}_{\mathrm{a}}$ was obtained at $0.1 \mathrm{wt} \%$ reinforcement from $0.382 \mu \mathrm{m}$ to $0.396 \mu \mathrm{m}(3.7 \% \mathrm{in}$ crease). The highest improvement was recorded for $1 \mathrm{wt} \%$ reinforcement varying from $0.382 \mu \mathrm{m}$ to $1.095 \mu \mathrm{m}$ (187\% increase). The maximum root mean square $\mathrm{R}_{\mathrm{q}}$ (Figure $8(\mathrm{f})$ ) value was also obtained in case of $1 \mathrm{wt} \%$ reinforcement from $0.48 \mu \mathrm{m}$ to $1.59 \mu \mathrm{m}$ (231.3\% increase). Significant increment in surface coarseness is an evident of crack deflection mechanism, which increase absorbed energy of fracture by increasing the crack length during deformation [10]. Microscale surface roughness likely produces enhanced mechanical interlocking with the polymer chains and better adhesion [50]. On the other hand, coarser topography profile of nanocomposites can be attributed to two factors; the presence of nano-particles and plasticization effect. Exfoliated halloysite particles tend to increase micro layers. Plasticization effect increase the crack zone size and peak height of nanocomposites exposed to methanol.

\section{SEM Images}

The methanol effect on the surface of monolithic polyester is shown in Figure 9(a). It can be observed that methanol penetrated through numbers of microvoids. In contrast, exfoliated halloysite nanoclay reinforcement offers environmental stress cracking resistance due to increase of tortuosity path. Exfoliated clay particles obtained from homogenous dispersion in polyester lead to the improvement in barrier properties. The exfoliated morphology proved to be better in increasing the path length due to high aspect ratio. The formation of large number of microcracks and the increase in the fracture surface area due to crack deflection are the major toughening mechanisms. Samples with $0.7 \mathrm{wt} \%$ reinforcement have good nano-filler dispersion. Moreover, significant micro cracks layer were observed from halloysite nanoclay reinforcement (Figure 9(d)). The formation of large number of micro-cracks responsible to higher resistance of crack advancement. The adhesion between halloysite nanoclay and the polyester matrix was very strong. For $1 \mathrm{wt} \%$ halloysite nanoclay-polyester, stress concentration was increased by agglomerates particles that lead to premature fracture. 


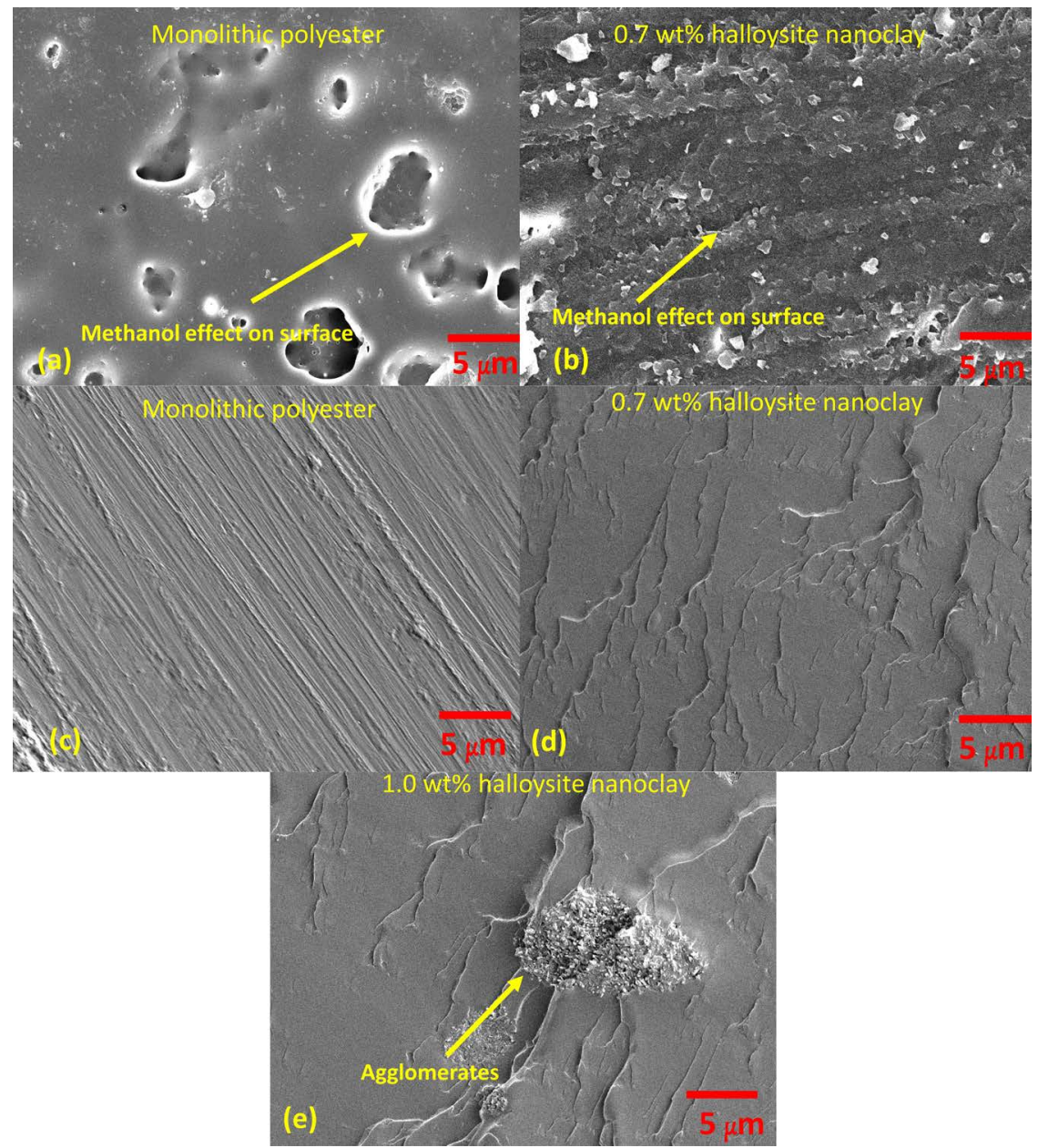

Figure 9. SEM Images of fractured surface.

The agglomeration of halloysite nanoclay act as stress concentrator as shown in Figure 9(e). This was the main factor that affecting the final properties of the 1 wt\% halloysite nanoclay-polyester nano-composites.

\section{Conclusion}

In this research work, the environmental stress cracking resistance of polyester and its nano-composites in methanol was investigated under the constant loading by using fracture mechanics approach. This study has shown that the environmental stress cracking effect can be reduced with the reinforcement of halloysite nanoclay. The monolithic polyester was severely affected from the direct contact with methanol compared to halloysite nanoclay-polyester nanocomposites. The maximum $K_{1 \mathrm{C}}$ was observed at $0.7 \mathrm{wt} \%$ reinforcement with $33 \% \mathrm{im}$ provement. The maximum time to failure and microhardness were also significantly improved by $155 \%$ and $119 \%$ (at $0.7 \mathrm{wt} \%$ nanoclay reinforcement) compared to monolithic polyester. This research extends our knowledge of the environmental stress cracking resistance of polyester-halloysite nanoclay. The incorporation of halloysite nanoclay into the polyester was able to reduce the effect of methanol exposure but further studies are required. It would be interesting to 
assess the effects of different clay based particles on the environmental stress cracking resistance of polyester using the similar fracture mechanics approach.

\section{Acknowledgements}

The authors fully acknowledged Northumbria University, UK, which makes this important research viable and effective.

\section{References}

[1] Saharudin, M.S., Jumahat, A., Kahar, A.Z., et al. (2013) The Influence of Alumina Filler on Impact Properties of Short Glass Fiber Reinforced Epoxy. Applied Mechanics and Materials, 393, 88-93.

[2] Saharudin, M.S., Shyha, I. and Inam, F. (2016) Viscoelastic and Mechanical Properties of Multi-Layered-Graphene Polyester Composites. 2nd International Conference on Advances in Mechanical Engineering, Istanbul, 10-13 May 2016, 41-45.

[3] Wei, J., Saharudin, M.S., Vo, T., et al. (2017) N,N-Dimethylformamide (DMF) Usage in Epoxy/Graphene Nanocomposites: Problems Associated with Reaggregation. Polymers, 9, 193. https://doi.org/10.3390/polym9060193

[4] Saharudin, M.S., Atif, R., Shyha, I. and Inam, F. (2016) The Degradation of Mechanical Properties in Polymer Nano-Composites Exposed to Liquid Media-A Review. RSC Advances, 6, 1076-1089. https://doi.org/10.1039/C5RA22620A

[5] Robeson, L.M. (2013) Environmental Stress Cracking: A Review. Polymer Engineering \& Science, 53, 453-467. https://doi.org/10.1002/pen.23284

[6] Akdemir, A., Tarakcioglu, N. and Avci, A. (2001) Stress Corrosion Crack Growth in Glasspolyester Composites with Surface Crack. Stress. The International Journal on the Biology of Stress, 32, 123-129.

[7] Friedrich, K. (1981) Stress Corrosion Crack Propagation in Glass Fibre Reinforced/ Thermoplastic PET. Journal of Materials Science, 16, 3292-3302.

https://doi.org/10.1007/BF00586289

[8] Morrison, E.D., Malvey, M.W., Johnson, R.D., et al. (2008) Effect of Chemical Environments on Stress Cracking of Poly(Ethylene Terephthalate) Beverage Bottles. Polymer Testing, 27, 660-666.

[9] Sahin, O.S., Akdemir, A., Avci, A., et al. (2008) Fatigue Crack Growth Behavior of Filament Wound Composite Pipes in Corrosive Environment. Journal of Reinforced Plastics and Composites, 28, 2957-2970.

[10] Alamri, H. and Low, I.M. (2012) Effect of Water Absorption on the Mechanical Properties of Nano-Filler Reinforced Epoxy Nanocomposites. Materials \& Design, 42, 214-222.

[11] Alamri, H. and Low, I.M. (2012) Microstructural, Mechanical, and thermal Characteristics of Recycled Cellulose Fiber-Halloysite-Epoxy Hybrid Nanocomposites. Polymer Composites, 33, 589-600. https://doi.org/10.1002/pc.22163

[12] Du, M., Guo, B. and Jia, D. (2006) Thermal Stability and Flame Retardant Effects of Halloysite Nanotubes on Poly(Propylene). European Polymer Journal, 42, 13621369.

[13] Wilson, I.R., de Souza Santos, H. and de Souza Santos, P. (2006) Kaolin and Halloysite Deposits of Brazil. Clay Minerals, 41, 697-716. https://doi.org/10.1180/0009855064130213

[14] Albdiry, M.T., Yousif, B.F. and Ku, H. (2013) Fracture Toughness and Toughening Mechanisms of Unsaturated Polyester-Based Clay Nanocomposites. Chinese Society of Theoretical and Applied Mechanics, 1-10. 
[15] Saharudin, M.S., Shyha, I. and Inam, F. (2015) The Effect of Methanol Exposure on the Flexural and Tensile Properties of Halloysite Nanoclay/Polyester. The IRES 17 th International Conference, London, 40-44.

[16] Kamble, R., Ghag, M., Gaikawad, S., et al. (2012) Review Article Halloysite Nanotubes and Applications: A Review. Journal of Advanced Scientific Research, 3, 25 29.

[17] Saharudin, M.S., Atif, R. and Inam, F. (2017) Effect of Short-Term Water Exposure on the Mechanical Properties of Halloysite Nanotube-Multi Layer Graphene Reinforced Polyester Nanocomposites. Polymers, 9, 27.

[18] Yuan, P., Tan, D. and Annabi-Bergaya, F. (2015) Properties and Applications of Halloysite Nanotubes: Recent Research Advances and Future Prospects. Applied Clay Science, 112, 75-93.

[19] Maisanaba, S., Pichardo, S., Puerto, M., et al. (2015) Toxicological Evaluation of Clay Minerals and Derived Nanocomposites: A Review. Environmental Research, 138, 233-254.

[20] Ward, A.L., Lu, X., Huang, Y., et al. (1991) The Mechanism of Slow Crack Growth in Polyethylene by an Environmental Stress Cracking Agent. Polymer, 32, 21722178 .

[21] Pons, N., Bergeret, A., Benezet, J.C., et al. (2011) An Environmental Stress Cracking (ESC) Test to Study the Ageing of Biopolymers and Biocomposites. Polymer Testing, 30, 310-317.

[22] Wright, D. (2006) Failure of Plastics and Rubber Products. Rapra Technology Limited.

[23] Hojo, H., Ogasawara, K., Chang, W. and Tsuda, K. (1994) Degradation Behavior of Unsaturated Polyester Resin in Alcohols. Advanced Composite Materials, 3, 341 353. https://doi.org/10.1163/156855194X00213

[24] Saharudin, M.S., Rasheed, A., Shyha, I. and Inam, F. (2016) The Degradation of Mechanical Proper Ties in Halloysite Nanoclay-Polyester Nanocomposites Exposed to Diluted Methanol. Journal of Composite Materials, 51, 1653-1664.

[25] Saharudin, M., Wei, J., Shyha, I. and Inam, F. (2016) The Degradation of Mechanical Properties in Halloysite Nanoclay-Polyester Nanocomposites Exposed in Seawater Environment. Journal of Nanomaterials, 2016, Article ID: 2604631.

[26] Saharudin, M.S., Wei, J., Shyha, I., et al. (2017) Flexural Properties of Halloysite Nanotubes-Polyester Nanocomposites Exposed to Aggressive Environment. International Journal of Chemical, Molecular, Nuclear, Materials and Metallurgical Engineering, 11, 292-296.

[27] Huang, G. and Sun, H. (2007) Effect of Water Absorption on the Mechanical Properties of Glass/Polyester Composites. Materials and Design, 28, 1647-1650.

[28] Moskala, E.J. (1998) A Fracture Mechanics Approach to Environmental Stress Cracking in Poly(Ethyleneterephthalate). Polymer, 39, 675-680.

[29] Bonnia, N.N., et al. (2010) Mechanical Properties and Environmental Stress Cracking Resistance of Rubber Toughened Polyester/Kenaf Composite. eXPRESS Polymer Letters, 4, 55-61. https://doi.org/10.3144/expresspolymlett.2010.10

[30] Gu, H. (2009) Behaviours of Glass Fibre/Unsaturated Polyester Composites under Sea Water Environment. Materials and Design, 30, 1337-1340.

[31] Swain, S. (2013) Synthesis and Characterization of Graphene Based Unsaturated Poly Ester Resin Composites. Transactions on Electrical and Electronic Materials, 14, 53-58. https://doi.org/10.4313/TEEM.2013.14.2.53 
[32] Lee, S.-B., Rockett, T.J. and Hoffman, R.D. (1992) Interactions of Water with Unsaturated Poly Ester, Vinyl Ester and Acrylic Resins. Polymer, 33, 3691-3697.

[33] Ku, H., Wang, H., Pattarachaiyakoop, N., et al. (2011) A Review on the Tensile Properties of Natural Fiber Reinforced Polymer Composites. Composites Part B: Engineering, 42, 856-873.

[34] Bromberg, L. and Cheng, W.K. (2010) Methanol as an Alternative Transportation Fuel in the U.S. Options for Sustainable and/or Energy-Secure Transportation. http://www.methanol.org/Energy/Resources/Alternative-Fuel/MIT-Methanol-Repo rt-Final-Nov-2010.aspx

[35] Atif, R. and Inam, F. (2016) Fractography Analysis of 0.5 wt\% Multi-Layer Graphene/ Nanoclay Reinforced Epoxy Nanocomposites. AIMS Materials Science, 3, 12661280 .

[36] Atif, R. and Inam, F. (2016) Influence of Macro-Topography on Damage Tolerance and Fracture Toughness of 0.1 wt\% Multi-Layer Graphene/Clay-Epoxy Nanocomposites. Polymers, 8, 239. https://doi.org/10.3390/polym8070239

[37] Atif, R., Shyha, I. and Inam, F. (2016) The Degradation of Mechanical Properties Due to Stress Concentration Caused by Retained Acetone in Epoxy Nanocomposites. RSC Advances, 6, 34188-34197. https://doi.org/10.1039/C6RA00739B

[38] Pramoda, K.P. and Liu, T. (2004) Effect of Moisture on the Dynamic Mechanical Relaxation of Polyamide-6/Clay Nanocomposites. Journal of Polymer Science, Part B: Polymer Physics, 42, 1823-1830. https://doi.org/10.1002/polb.20061

[39] Wu, Z., Zhou, C., Qi, R. and Zhang, H. (2002) Synthesis and Characterization of Nylon 1012/Clay Nanocomposite. Journal of Applied Polymer Science, 83, 2403 2410. https://doi.org/10.1002/app.10198

[40] Senthil Kumar, M.S., Mohana Sundara Raju, N., Sampath, P.S., et al. (2015) Tribological Analysis of Nano Clay/Epoxy/Glass Fiber by Using Taguchi's Technique. Materials \& Design, 70, 1-9.

[41] Zhang, K., Wang, L., Wang, F., et al. (2004) Preparation and Characterization of Modified-Clay-Reinforced and Toughened Epoxy-Resin Nanocomposites. Journal of Applied Polymer Science, 91, 2649-2652. https://doi.org/10.1002/app.13445

[42] Zainuddin, S., Hosur, M.V., Zhou, Y., et al. (2009) Durability Studies of Montmorillonite Clay Filled Epoxy Composites under Different Environmental Conditions. Materials Science and Engineering A, 507, 117-123.

[43] Guo, B., Zou, Q., Lei, Y. and Jia, D. (2009) Structure and Performance of Polyamide 6/Halloysite Nanotubes Nanocomposites. Polymer Journal, 41, 835-842. https://doi.org/10.1295/polymj.PJ2009110

[44] Atif, R., Wei, J., Shyha, I., et al. (2016) Use of Morphological Features of Carbonaceous Materials for Improved Mechanical Properties of Epoxy Nanocomposites. RSC Advances, 6, 1351-1359. https://doi.org/10.1039/C5RA24039E

[45] Asadi, J., Ebrahimi, N.G. and Razzaghi-Kashani, M. (2015) Composites: Part A Self-Healing Property of Epoxy/Nanoclay Nanocomposite Using Poly (Ethylene-coMethacrylic Acid) Agent. Composites Part A, 68, 56-61.

[46] Sahoo, N.G., Rana, S., Cho, J.W., et al. (2010) Polymer Nanocomposites Based on Functionalized Carbon Nanotubes. Progress in Polymer Science, 35, 837-867.

[47] Chieruzzi, M., Miliozzi, A. and Kenny, J.M. (2013) Effects of the Nanoparticles on the Thermal Expansion and Mechanical Properties of Unsaturated Polyester/Clay Nanocomposites. Composites Part A: Applied Science and Manufacturing, 45, 4448 . 
[48] Arnold, J.C. (1998) The Effects of Diffusion on Environmental Stress Crack Initiation in PMMA. Journal of Materials Science, 33, 5193-5204.

https://doi.org/10.1023/A:1004431920449

[49] Shi, X., Nguyen, T.A., Suo, Z., et al. (2009) Effect of Nanoparticles on the Anti Corrosion and Mechanical Properties of Epoxy Coating. Surface and Coatings Technology, 204, 237-245.

[50] Ramanathan, T., Abdala, A.A., Stankovich, S., et al. (2008) Functionalized Graphene Sheets for Polymer Nanocomposites. Nature Nanotechnology, 3, 327-331.

https://doi.org/10.1038/nnano.2008.96

Submit or recommend next manuscript to SCIRP and we will provide best service for you:

Accepting pre-submission inquiries through Email, Facebook, LinkedIn, Twitter, etc. A wide selection of journals (inclusive of 9 subjects, more than 200 journals)

Providing 24-hour high-quality service

User-friendly online submission system

Fair and swift peer-review system

Efficient typesetting and proofreading procedure

Display of the result of downloads and visits, as well as the number of cited articles

Maximum dissemination of your research work

Submit your manuscript at: http://papersubmission.scirp.org/

Or contact wjet@scirp.org 